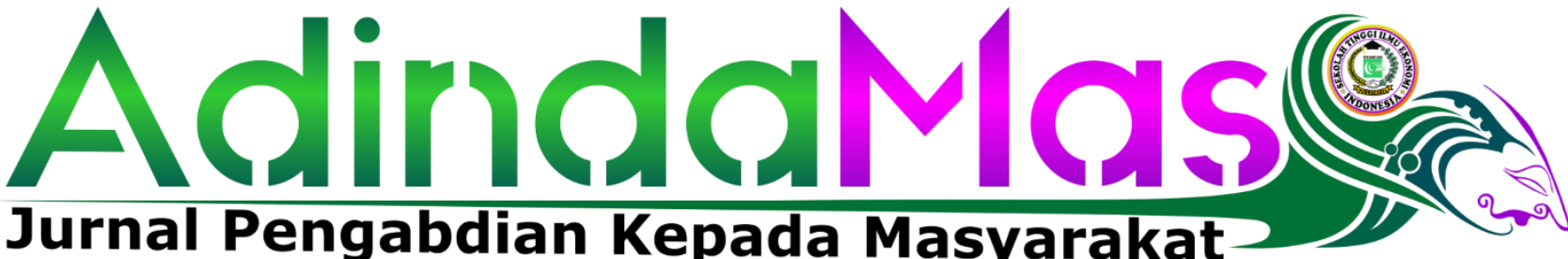

Volume 1 Nomor 1, Juli 2021

\section{Sosialisasi Sosial Ekonomi Dan Budaya Ibadah Qurban Di Pondok Pesantren Miftahurrohmah Sukarata Purwakarta}

\author{
Jalaludin ${ }^{1}$, Ahmad Ali Sopian², Eka Ahadiyat Suryana ${ }^{3 *}$ \\ 1 Sekolah Tinggi Iilmu Ekonomi Syariah (STIES) Indonesia Purwakarta \\ 1jalaludin@sties-purwakarta.ac.id \\ 2 Mahsiswa Sekolah Tinggi Iilmu Ekonomi Syariah (STIES) Indonesia Purwakarta \\ 2aalsopian24@gmail.com \\ ${ }^{3}$ Universitas Islam Negeri (UIN) Sunan Gunung Djati Bandung \\ 3eka.ahadiyat@gmail.com
}

\begin{abstract}
ABSTRAK
Ibadah qurban merupakan ibadah pemotongan hewan qurban yang diselenggarakan setiap tahun oleh umat muslim diseluruh dunia tepatnya saat merayakan hari raya idul adha. Dengan demikian, ibadah qurban secara tidak langsung akan berdampak terhadap kondisi sosial ekonomi dan budaya masyarakat dimana ibadah qurban tersebut dilaksanakan. Dari aspek sosial ekonomi ibadah qurban tidak hanya hanya sebatas ritual kegamaan semata tetapi juga bisa sebagai penggerak perekonomian masyarakat terutama dalam pengadaan hewan qurban. Selanjutnya dalam aspek sosial budaya adalah bagaimana ibadah qurban dapat mengubah gaya hidup umat menjadi lebih sederhana yang jauh dari sifat konsumerisme dan gaya hidup berlebihan. Permasalahan yang selama ini terjadi di masyarakat adalah kurangnya kesadaran masyarakat (jamaah) tentang hikmah dari ibadah qurban terutama dari aspek sosial ekonomi dan budaya. Pengabdian kepada masyarakat ini dilakukan untuk meningkatkan kesadaran masyarakat (jamaah) terhadap hikmah dari ibadah qurban terutama dari aspek sosial ekonomi dan budaya. Kegiatan ini dilakukan di Pondok Pesantren Miftahurrohmah Sukarata Kab. Purwakarta. Pendekatan yang dilakukan adalah ceramah dan diskusi, yaitu dengan memberikan penjelasan materi secara tutorial dan diskusi serta memberikan contoh pengelolaan dan pelaksanaan ibadah qurban yang dapat meningkatkan dampak sosial ekonomi dan budaya masyarakat.
\end{abstract}

ADINDAMAS (Jurnal Pengabdian Kepada Masyarakat), Volume 1, Nomor 1, Juli 2021 http://journal.sties-purwakarta.ac.id/index.php/adindamas/

ISSN: xxxx-xxxx (Media Online) xxxx-xxxx (Media Cetak) 
Kata kunci - Budaya, Sosial Ekonomi, Ibadah Qurban.

\section{ABSTRACT}

Sacrificial worship is the worship of slaughtering sacrificial animals which is held every year by Muslims around the world, precisely when celebrating Eid al-Adha. Thus, the qurban worship will indirectly have an impact on the socio-economic and cultural conditions of the community where the qurban worship is carried out. From the socio-economic aspect, qurban worship is not only limited to religious rituals but can also be a driving force for the community's economy, especially in the procurement of sacrificial animals. Next in the socio-cultural aspect is how qurban worship can change people's lifestyles to be simpler which is far from consumerism and excessive lifestyles. The problem that has occurred in the community is the lack of public awareness (congregations) about the wisdom of qurban worship, especially from the socio-economic and cultural aspects. This community service is carried out to increase public awareness (congregations) of the wisdom of qurban worship, especially from the socio-economic and cultural aspects. This activity was carried out at the Miftahurrohmah Islamic Boarding School Sukarata Kab. Purwakarta. The approach taken is lectures and discussions, namely by providing explanations of the material in tutorials and discussions as well as providing examples of the management and implementation of qurban worship that can increase the socioeconomic and cultural impact of the community.

Keywords - Culture, Socio-Economic, Sacrifice Worship.

\section{PENDAHULUAN}

Ibadah qurban setiap tahunnya dilaksanakan bertepatan dengan pelaksanaan ibadah haji yaitu pada bulan Dzulhijjah yang merupakan hari besar umat islam yang disebut hari Idul Adha ${ }^{1}$. Pada hari raya ini sebagian besar umat islam akan menyembelih hewan Qurban khususnya diselenggarakan bagi umat muslim yang mampu, sebagaimana diperintahkan Allah SWT dalam surah al-Kautsar (108): 1-2.

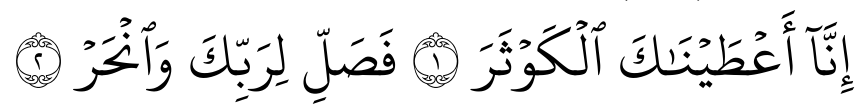

"Sesungguhnya Kami telah memberikan kepadamu nikmat yang banyak. Maka dirikanlah shalat karena Tuhan-mu dan berQurbanlah."2

Surat Al-Hajj Ayat 34

${ }^{1}$ Abdullah Nur, "Ibadah Qurban Dalam Perspektif Hadis," Rausyan Fikr: Jurnal Studi Ilmu Ushuluddin dan Filsafat 12, no. 1 (2016): 144-160.

2 Team Al-Fatih Berkah Cipta, Al-Quranul Karim: Tafsir Perkata Tajwid Kode Arab (Jakarta Timur: PT. Insan Media Pustaka, 2012), 602.

ADINDAMAS (Jurnal Pengabdian Kepada Masyarakat), Volume 1, Nomor 1, Juli 2021

http://journal.sties-purwakarta.ac.id/index.php/adindamas/

ISSN: xxxx-xxxx (Media Online) xxxx-xxxx (Media Cetak) 


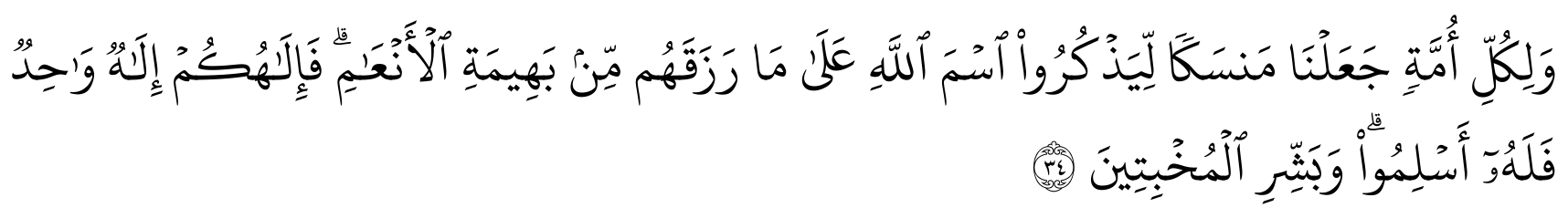

"Dan bagi tiap-tiap umat telah kami syariatkan penyembelihan (qurban) supaya mereka menyebut nama Allah terhadap binatang ternak yang telah direzekikan Allah kepada mereka, maka Tuhanmu ialah Tuhan yang Maha Esa, karena itu berserahdirilah kamu kepada-Nya, dan berilah kabar gembira pada orang-orang yang tunduk (patuh) pada Allah." (QS: Al-Hajj: 34) ${ }^{3}$

Dalam ayat di atas, disebutkan bahwa penyembelihan hewan kurban yang berorientasi kepada Allah SWT adalah sebagai bentuk syukur dan berserah diri kita kepada Allah SWT4. Hewan-hewan kurban adalah sebagai salah satu bentuk rezeki yang Allah berikan kepada kita. Menyembelihnya satu saja dari setiap muslim, tentu tidak akan mengurangi rezeki yang telah Allah berikan kepada kita. ${ }^{5}$

Selain itu, dilanjutkan kembali oleh ayat QS: Al-Hajj ayat 36-37,

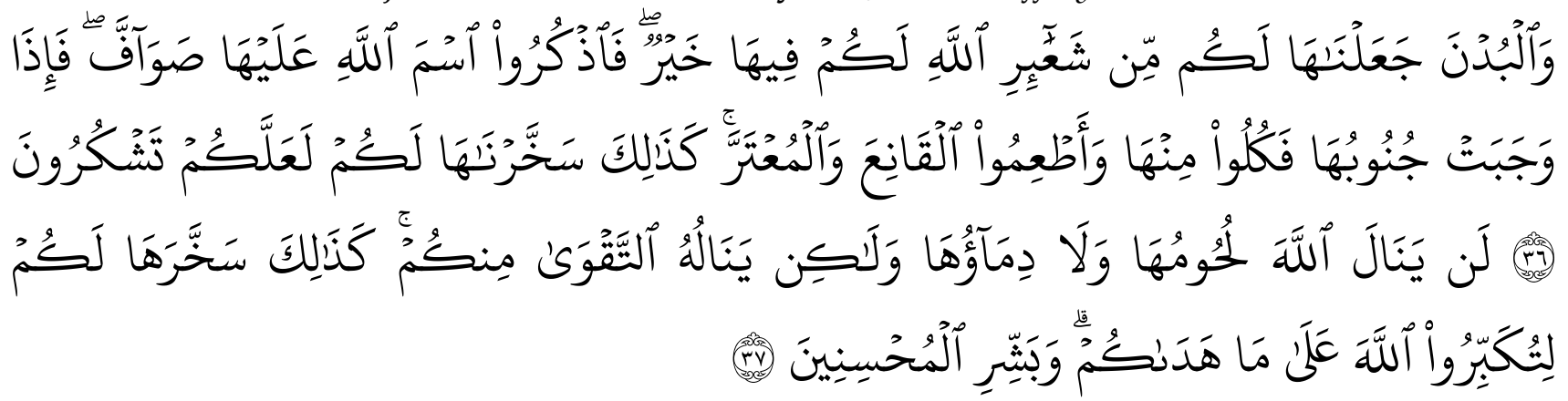

"Dan telah Kami jadikan untuk kamu unta-unta itu sebahagian dari syi'ar Allah, kamu memperoleh kebaikan yang banyak padanya, maka sebutlah olehmu nama Allah ketika kamu menyembelihnya dalam keadaan berdiri (dan telah terikat). Kemudian apabila telah roboh (mati), maka makanlah sebahagiannya dan beri makanlah orang yang rela dengan apa yang ada padanya (yang tidak meminta-minta) dan orang yang meminta. Demikianlah Kami telah menundukkan untua-unta itu kepada kamu, mudah-mudahan kamu bersyukur. Daging-daging unta dan darahnya itu sekali-kali tidak dapat mencapai (keridhaan) Allah, tetapi ketakwaan dari kamulah yang dapat mencapainya. Demikianlah Allah telah menundukkannya untuk kamu supaya kamu mengagungkan Allah terhadap hidayah-Nya kepada kamu. Dan berilah kabar gembira kepada orang-orang yang berbuat baik." (QS: Al-Hajj ayat 36-37)6

Perintah berkurban juga tidak mengurangi rasa syukur dan kenikmatannya, karena sebagai orang yang berkurban, maka berhak juga untuk menikmatinya

\footnotetext{
3 Ibid., 336.

${ }^{4}$ Hubbul Wathan, "Pandangan Ulama Kota Medan Tentang Pelaksanaan Iddikhar Daging Qurban Di Rumah Zakat Medan-Sumatera Utara," Human Falah: Jurnal Ekonomi dan Bisnis Islam 4, no. 1 (2017).

${ }^{5}$ Jalaluddin As-Suyuthi and Jalaluddin Muhammad Ibnu Ahmad Al-Mahally, Tafsir Jalalain (Terjemahan), Imaratullah (Surabaya: Imaratullah, 2003), 128.

6 Team Al-Fatih Berkah Cipta, Al-Quranul Karim: Tafsir Perkata Tajwid Kode Arab, 336.
}

ADINDAMAS (Jurnal Pengabdian Kepada Masyarakat), Volume 1, Nomor 1, Juli 2021 http://journal.sties-purwakarta.ac.id/index.php/adindamas/

ISSN: xxxx-xxxx (Media Online) xxxx-xxxx (Media Cetak) 
sebagian dan tentunya menjadi kenikmatan juga bagi para penerima manfaat yang menerimanya. ${ }^{7}$ Output dari ibadah kurban adalah ketaqwaan, untuk itu seperti ayat di atas sebutkan bahwa bukan darah dagingnya yang mencapai keridhoaan Allah, tapi bagaimana kita bertaqwa atas-Nya.

Selain ayat Al-Qur'an, seruan berqurban juga bisa ditemukan pada hadits Rasulullah:

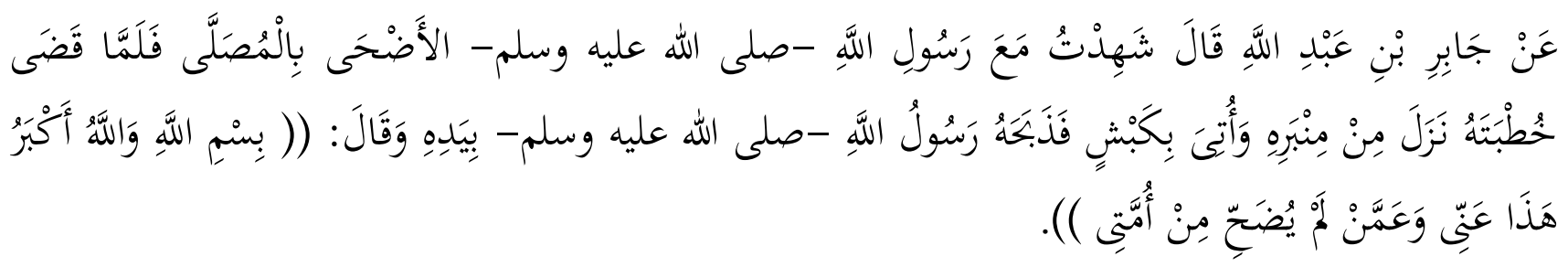

"Diriwayatkan dari Jabir bin 'Abdillah radhiallahu' 'anhu bahwasanya dia berkata, "Saya menghadiri shalat idul-Adha bersama Rasulullah shallallahu 'alaihi wa sallam di mushalla (tanah lapang). Setelah beliau berkhutbah, beliau turun dari mimbarnya dan didatangkan kepadanya seekor kambing. Kemudian Rasulullah shallallahu 'alaihi wa sallam menyembelihnya dengan tangannya, sambil mengatakan: Dengan nama Allah. Allah Maha Besar. Kambing ini dariku dan dari orang-orang yang belum menyembelih di kalangan umatku." 8

HR. Imam Ahmad dan Ibnu Majah

"Barangsiapa mendapatkan kelapangan tetapi tidak berkurban, maka janganlah dia mendekati tempat salat kami." (HR. Imam Ahmad dan Ibnu Majah). ${ }^{9}$

HR. Ibn Majah dan Tirmidzi

Dari Aisyah, Rasulullah SAW bersabda: "Tidak ada amalan anak cucu Adam pada hari raya qurban yang lebih disukai Allah melebihi dari mengucurkan darah (menyembelih hewan qurban), sesungguhnya pada hari kiamat nanti hewan-hewan tersebut akan datang lengkap dengan tanduk-tanduknya, kuku-kukunya, dan bulu- bulunya. Sesungguhnya darahnya akan sampai kepada Allah-sebagai qurban-di manapun hewan itu disembelih sebelum darahnya sampai ke tanah, maka ikhlaskanlah menyembelihnya." (HR. Ibn Majah dan Tirmidzi). ${ }^{10}$

Untuk itu, dari hadist di atas, kita bisa mendapatkan banyak hikmah bahwa perintah berqurban adalah perintah yang sangat ditekankan baik oleh Allah SWT melalui Al-Quran dan hadits-hadits yang mencerminkan teladan Rasulullah SAW. Jika kita memiliki kelebihan harta, kelapangan untuk berqurban di tahun ini, maka segerakanlah agar menjadi manfaat luas bagi sesama dan kebaikan bagi kita di dunia

7 As-Suyuthi and Al-Mahally, Tafsir Jalalain (Terjemahan), 128.

${ }^{8}$ Muhammad Sirojuddin Cholili, "Problematika Seputar Ibadah Qurban," Modeling: Jurnal Program Studi PGMI 2, no. 2 (2015).

${ }_{9}$ Wathan, "Pandangan Ulama Kota Medan Tentang Pelaksanaan Iddikhar Daging Qurban Di Rumah Zakat Medan-Sumatera Utara."

${ }^{10}$ Cholili, "Problematika Seputar Ibadah Qurban."

ADINDAMAS (Jurnal Pengabdian Kepada Masyarakat), Volume 1, Nomor 1, Juli 2021

http://journal.sties-purwakarta.ac.id/index.php/adindamas/

ISSN: xxxx-xxxx (Media Online) xxxx-xxxx (Media Cetak) 
maupun di akhirat ${ }^{11}$. Terlebih jika qurban kita pun dapat menjangkau banyak orang yang membutuhkan dan mengukir senyum kebahagiaan untuk mereka. Makna dari ibadah Qurban sangat dalam dan luas. Bukan sekadar ibadah tahunan yang bernilai spiritual-sosial. Lebih jauh lagi, esensi dari Qurban adalah membangun kerangka ekonomi dan budaya umat Islam.

\section{A. Nilai Sosial Ekonomi}

Sebagaimana halnya zakat, infak, sedekah, dan wakaf, Qurban memiliki kekuatan penggerak ekonomi. Tentu saja itu dapat terjadi jika dikelola dengan baik. Sayangnya, hingga saat ini belum ada lembaga nasional yang secara khusus menangani Qurban. Atau paling tidak, ada koordinasi antar lembaga dalam melaksanakan Qurban Dari data tiap lembaga tersebut, dapat diperoleh informasi di mana saja daerah yang banyak melakukan ibadah Qurban, di mana yang tidak mendapatkan hewan Qurban, siapa saja yang berQurban dan penerimanya, berapa jumlah dan data-data terkait lainnya ${ }^{12}$. Ini sangat penting karena jika tidak dilakukan, ibadah Qurban sepertinya kurang memiliki dampak ekonomi dan sosial apa pun. Setiap tahun kegiatan Qurban hanya membeli, menyerahkan kepada panitia, dan membagikannya, setelah itu selesai.

Selama ini koordinasi yang baik antar lembaga atau organisasi kemasyarakatan islam belum terlaksana. Oleh karena itu perlu adanya partisipasi pihak-pihak yang berkepentingan seperti Majelis Ulama Indonesia (MUI) memberikan arahan pentingnya koordinasi data dan program dalam pelaksanaan ibadah Qurban. Dengan demikian, pembenahan sistem organisasi dan manajemen Qurban mutlak harus dilakukan. Jika saja pengelolaan Qurban dilakukan dengan sistem manajemen yang sangat baik, maka akan menjadi suatu strategi ekonomi umat yang luar biasa.

Asumsikan saja, jika hanya 100 ribu orang yang melakukan ibadah Qurban, maka ada dana lebih dari Rp 200 miliar yang berputar. Bisa saja jumlahnya lebih dari 500 ribu orang karena ada banyak yang berqurban lebih dari satu. Artinya, ada dana Rp 1 triliun lebih yang berputar dalam waktu menjelang dan selama kegiatan ibadah Qurban dilakukan. Belum lagi jika kita menghitung multiplayer effect-nya. Hingga kini, tidak diketahui pasti, berasal dari mana hewan Qurban yang diperdagangkan. Agar sesuai syariah, pemasok hewan Qurban adalah ormas Islam atau lembaga zakat. Jika pun pemain kecil tetap ada, harus dikoordinasikan dan dipayungi oleh lembaga ekonomi umat yang besar, baik itu dikelola dalam bentuk koperasi syariah atau

${ }^{11}$ Mohamad Syahriar and Mohamad Syahriar, "Representasi Makna Qurban Dalam Budaya Populer: Membaca Konsumerisme Melalui Analisis Semiotika Barthes Iklan Cetak PKPU Kurbanmu Kendaraanmu," LISKI: Lingkar Studi Komunikasi 2, no. 2 (2016): 147-179.

${ }^{12}$ Muhammadrodee Ka-nga, Mawardi Djalaluddin, and Nur Taufiq Sanusi, "Hukum Distribusi Daging Qurban Kepada Non-Muslim Menurut Pandangan Majlis Agama Islam Provinsi Pattani Thailand Selatan," Jurnal Diskursus Islam 4, no. 2 (2016): 285-300.

ADINDAMAS (Jurnal Pengabdian Kepada Masyarakat), Volume 1, Nomor 1, Juli 2021 http://journal.sties-purwakarta.ac.id/index.php/adindamas/

ISSN: xxxx-xxxx (Media Online) xxxx-xxxx (Media Cetak) 
lembaga lainnya..$^{13}$ Jangan sampai, peluang bisnis besar ini dipegang segelintir orang yang tak ada kontribusi dan bukan bagian dari umat Islam. Sepertinya rumit, tapi ini sudah seharusnya dapat dilakukan.

Menurut Iu Rushana, ada beberapa argumentasi mengapa pengelolaan ibadah Qurban harus diperbaiki manajemennya. 1) Makna spiritual Qurban itu adalah mengekang sifat kebinatangan, duniawi yang dominan. Jika ego antar lembaga masih tetap dipelihara, tidak mau sinergi satu sama lain, sama saja dengan memelihara sifat duniawi. 2) Lembaga atau panitia hanyalah pihak ketiga yang diamanahi untuk mengelola dan memfasilitasi ibadah Qurban itu. Harusnya koordinasi data dan sinergi program dapat dilakukan karena Qurban dilakukan setiap tahun. 3) Qurban, sebagaimana zakat, infak, sedekah, dan wakaf adalah bentuk kepedulian yang berpunya (aghniya) kepada yang kekurangan (dhuafa). Tujuannya mendorong pemerataan kesejahteraan ekonomi dan sosial. Harusnya bisa dibentuk panitia Qurban nasional, daerah hingga tingkat DKM (masjid). 4) Qurban harus jadi salah satu pemicu lahirnya industri peternakan dan perdagangan milik umat. Sesuai ajaran islam bahwa umatnya untuk produktif dan memiliki nilai manfaat besar. 5) secara historis, Rasulullah SAW dan sahabat kebanyakan adalah peternak dan penggembala. Dan ini merupakan potensi ekonomi yang tidak akan habis karena kebutuhan akan daging dan susu umat tidak akan pernah berkurang.

\section{B. Nilai Sosial Budaya}

Makna simbolik Qurban adalah mengekang sifat kebinatangan dan keduniawian. Qurban hendaknya menjadi nilai budaya untuk menjaga dari kecenderungan konsumerisme dan gaya hidup berlebihan (boros). Budaya hidup sederhana harus dijadikan keseharian umat. Inilah salah satu strategi kebudayaan yang mendesak dilakukan. Umer Chapra dalam bukunya Islam and Economic Development menyatakan, umat Islam harus bersikap kritis dan mampu membedakan antara kebutuhan yang penting dan yang kurang penting. ${ }^{14}$ Sehingga, dapat dibedakan antara kebutuhan dengan kemewahan. Dari perspektif budaya Islam, Qurban artinya sikap budaya yang mengedepankan kebutuhan primer dan pentingnya berbagi dengan sesama dibandingkan hidup bermewah-mewahan.

Umat Islam harus menghindari konsumsi yang berlebih-lebihan. Dengan ibadah Qurban, sifat kebinatangan dibuang dan sifat kepedulian kepada sesama ditumbuh suburkan. Kaum berlebih dari sisi ekonomi (aghniya) memberikan kontribusi tidak hanya dengan zakat, infak, wakaf, dan sedekah, tetapi juga dengan berqurban. Bahkan, sebagaimana diajarkan oleh Nabi Ibrahim AS, kecintaan kepada anak dan

${ }^{13}$ Aan Awaludin, "Program Pengabdian Kepada Masyarakat Teknik Handling Dan Penyembelihan Hewan Qurban," JPMP: Jurnal Pengabdian Masyarakat 2, no. 2 (2017): 84-97.

${ }^{14}$ Fadllan Fadllan, "Rekonstruksi Pembangunan Ekonomi Berbasis Islam Telaah Pemikiran M. Umer Chapra," NUANSA: Jurnal Penelitian Ilmu Sosial dan Keagamaan Islam 15, no. 2 (December 18, 2018): 393, http://ejournal.stainpamekasan.ac.id/index.php/nuansa/article/view/2064.

ADINDAMAS (Jurnal Pengabdian Kepada Masyarakat), Volume 1, Nomor 1, Juli 2021 
harta tidak boleh menghalangi kecintaan kepada Allah SWT. ${ }^{15}$ Jika Tuhan telah meminta apa pun yang paling dicintai, maka kita harus rela memberikannya.

Sebagaimana Nabi Ismail AS, anak terkasih yang ditunggu bertahun-tahun oleh Nabi Ibrahim AS, direlakan untuk disembelih demi menjalankan perintah Tuhan. Cinta kepada Tuhan di atas segala hal yang paling dicintai sekalipun di dunia ini. Jika dikaitkan dengan budaya cinta dunia yang mendominasi saat ini, harusnya Qurban memberi nilai yang mampu membuat seorang Muslim mengedepankan kecintaan kepada Tuhan dibandingkan kepada harta benda yang pasti habis dan rusak. ${ }^{16}$ Oleh karena itu, ibadah Qurban tidak hanya sekadar ritualitas dan pemenuhan kebutuhan gizi bagi umat yang kurang mampu. Ibadah Qurban harus menjadi strategi ekonomi dan kebudayaan agar umat Islam mandiri, sejahtera, dan berdaulat.

Dari penjelasan di atas dapat diungkapkan beberapa masalah yang umumnya dihadapi oleh pihak mitra terkait dengan hikmah dari ibadah qurban, yaitu: 1 . Kurangnya kesadaran masyarakat (jamaah) tentang esensi dari ibadah qurban; 2. Hikmah ibadah qurban ditinjau dari aspek sosial ekonomi; 3. Hikmah ibadah qurban dari aspek sosial budaya.

Tujuan Kegiatan dan rencana pemecahan masalah kegiatan pengabdian kepada masyarakat ini bertujuan untuk: (1) meningkatkan kesadaran masyarakat (jamaah) tentang esensi dari ibdah qurban, (2) memberikan pemahaman tentang hikmah ibadah qurban ditinjau dari aspek sosial ekonomi (3) memberikan pengetahuan tentang hikmah ibadah qurban ditinjau dari aspek sosial budaya.

\section{METODE}

\section{A. Tempat dan Waktu}

Kegiatan pengabdian kepada masyarakat tentang Sosialisasi Sosial Ekonomi Dan Budaya Ibadah Qurban Di Pondok Pesantren Miftahurrohmah Sukarata Purwakarta, pada hari minggu, tanggal 21-22 Agustus 2018 / 9-10 Dzulhijjah 1439 H.

\section{B. Ruang Lingkup dan Objek Pengabdian}

Objek yang menjadi sasaran dari kegiatan pengabdian kepada masyarakat ini adalah para jamaah dan Dewan Pengurus Pondok Pesantren Miftahurrohmah Sukarata Purwakarta yang beralamat di Jl. Cipaisan Gg. Sukarata Bawah RT 25 RW 06 Kelurahan Cipaisan, Kec/Kab. Purwakarta.

\footnotetext{
${ }^{15}$ Evi Marlina et al., “Wawancara Tentang Tinjauan Sosial Ekonomi Dan Budaya Ibadah Qurban,” Jurnal Pengabdian UntukMu NegeRI 3, no. 2 (November 5, 2019): 243-247, http://ejurnal.umri.ac.id/index.php/PengabdianUMRI/article/view/1564. Qurban."

${ }^{16}$ Awaludin, "Program Pengabdian Kepada Masyarakat Teknik Handling Dan Penyembelihan Hewan
}

ADINDAMAS (Jurnal Pengabdian Kepada Masyarakat), Volume 1, Nomor 1, Juli 2021 http://journal.sties-purwakarta.ac.id/index.php/adindamas/

ISSN: $x x x x-x x x x$ (Media Online) $x x x x-x x x x$ (Media Cetak) 


\section{Pendekatan atau teknik pengabdian}

Kegiatan pengabdian ini dilakukan dengan menggunakan pendekatan ceramah dan diskusi dengan jamaah dan Dewan Pengurus Pondok Pesantren Miftahurrohmah Sukarata Purwakarta terkait tinjauan ibadah qurban dari aspek sosial ekonomi dan budaya. Adapun langkah-langkah yang dilakukan yaitu: (1) meningkatkan kesadaran jamaah dan dewan pengurus tentang esensi ibadah qurban, (2) memberikan pemahaman tentang hikmah ibadah qurban ditinjau dari aspek sosial ekonomi dan (3) memberikan pemahaman tetag hikmah ibadah qurban ditinjau dari aspek sosial budaya.

\section{HASIL DAN PEMBAHASAN}

Kegiatan pengabdian kepada masyarakat ini diawali dengan persiapan pelaksaan kegiatan, yaitu persiapan tim dengan melakukan rapat koordinasi, pembuatan surat undangan, penyebaran undangan kepada jamaah dan dewan pengurus Dewan Pengurus Pondok Pesantren Miftahurrohmah Sukarata Purwakarta. Kegiatan selanjutnya adalah persiapan kelengkapan kegiatan yang meliputi hal-hal sebagai berikut: 1 . Mempersiapkan tempat pelaksanaan kegiatan pengabdian yaitu Pondok Pesantren Miftahurrohmah Sukarata Purwakarta; 2. Mempersipkan media presentasi, yaitu slide presentasi dan Infocus/LCD; 3. Pembuatan modul yang akan digunakan dalam ceramah dan diskusi.

Modul tersebut dibuat oleh pemateri dengan cakupan berupa materi-materi yang akan diberikan dalam kegiatan pengabdian. Modul tersebut dibuat dalam bentuk tutorial, teori dan contoh pelaksanaan ibadah qurban.

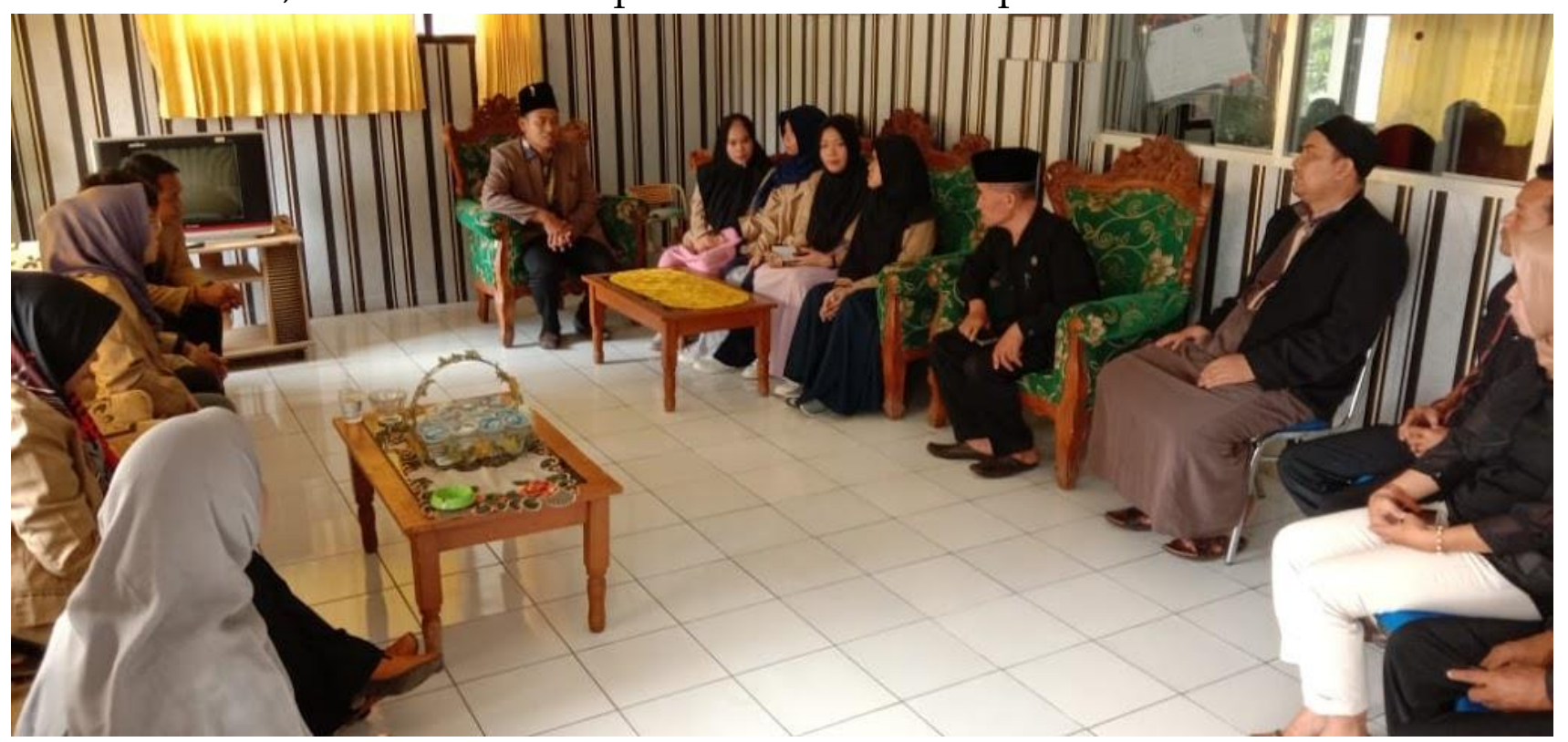

Gambar 1. Kegiatan Sosialisasi dan Ceramah 
Dalam kegiatan ceramah dan diskusi tersebut, hanya satu orang pemateri yang memberikan penjelasan tentang tinjauan aspek sosial ekonomi dan budaya ibadah qurban. Permasalahan-permasalahan yang selama ini hanya memandang ibadah qurban hanya proses ritual kegiatan keagamaan semata tanpa menyadari bahwa ibadah qurban juga mempunyai hikmah yang lebih luas.

Materi pengabdian diberikan selama lebih kurang satu jam dan kemudian dilanjutkan dengan diskusi antara peserta dengan pemateri. Pada sesi diskusi, para peserta terlihat sangat antusias menyampaikan pertanyaanpertanyaan terkait dengan permasalahan tentang ibadah qurban yang telah dilaksanakan selama ini. Sesi diskusi ini memberikan ruang dan suasana kedekatan antara peserta dan panitia maupun pemateri. Banyak peserta yang menyampaikan saran kepada panitia agar kegiatan seperti ini terus dilakukan dalam rangka untuk meningkatkan pemahaman jamaah dan dewan pengurus Pondok Pesantren Miftahurrohmah Sukarata Purwakarta dalam pengelolaan ibadah qurban.

Di hari berikut pengabdian kepada masyarakat di Pondok Pesantren Miftahurrohmah Sukarata Purwakarta untuk penyembelihan sekaligus pembagian hewan qurban kepada para mustahik, yang diserahkan oleh masing-masing pejabat RT setempat yaitu RT 25, RT 20, RT 19, RT 18, RT 21 dan RT 23 yang ada di lingkungan kelurahan Cipaisan Purwakarta. ${ }^{17}$ Semua Ketua RT tersebut dirangkul oleh Dewan Pengurus Pondok Pesantren Miftahurrohmah Sukarata Purwakarta untuk mendata mustahik penerima daging Qurban sebagai bahan untuk penyesuaian timbangan/ takaran dan jumlah paket daging yang harus disediakan oleh panitia.

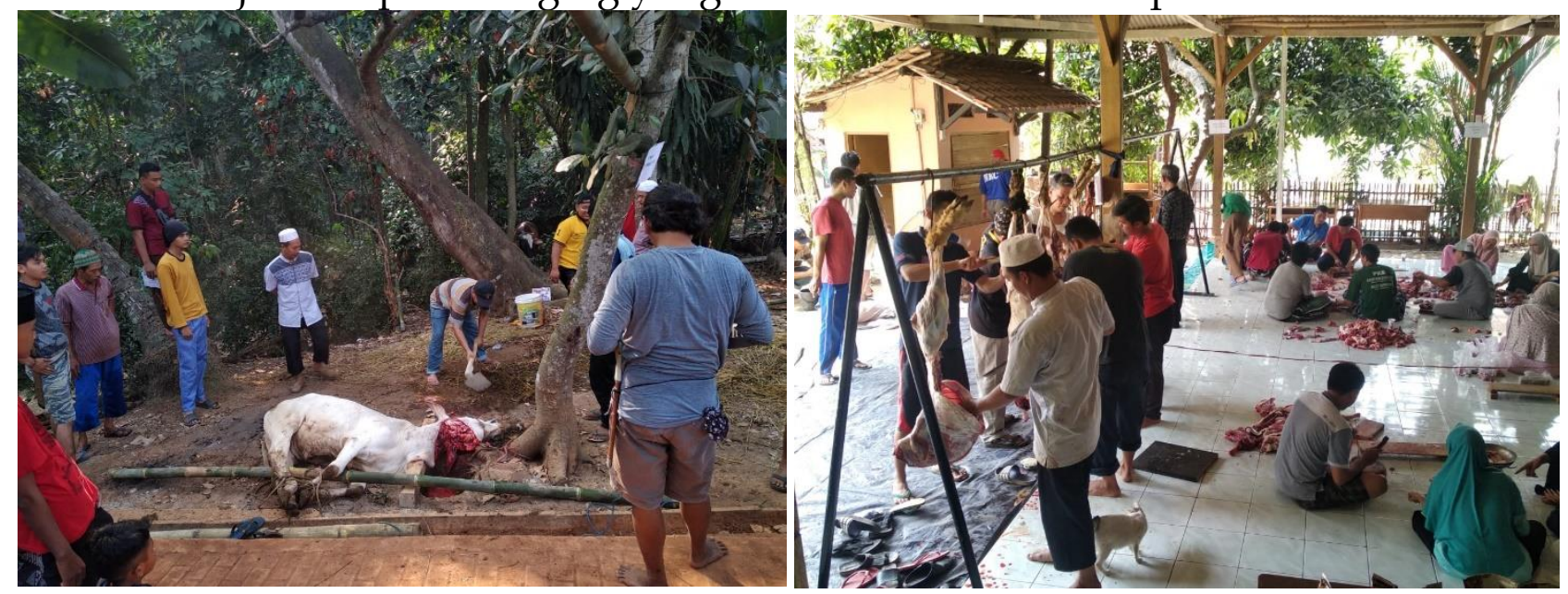

Gambar 2. Kegiatan Penyembelihan Hewan Qurban

Pembagian daging qurban kepada para mustahik daging qurban dimulai pada jam 13.00 WIB hingga jam 16.00 WIB, jika dalam rentang waktu tersebut masih

17 Iip Saripudin, “Budaya Ibadah Qurban Di Lingkungan Pondok Pesantren Miftahurrohmah Sukarata Purwakarta” (Purwakarta: Ketua Yayasan Miftahurrohmah Sukarata Purwakarta, 2018).

ADINDAMAS (Jurnal Pengabdian Kepada Masyarakat), Volume 1, Nomor 1, Juli 2021 http://journal.sties-purwakarta.ac.id/index.php/adindamas/

ISSN: xxxx-xxxx (Media Online) xxxx-xxxx (Media Cetak) 
terdapat mutahik dagung qurban belum mengambil bagiannya, maka panitia akan mengantarkan ke rumahnya.
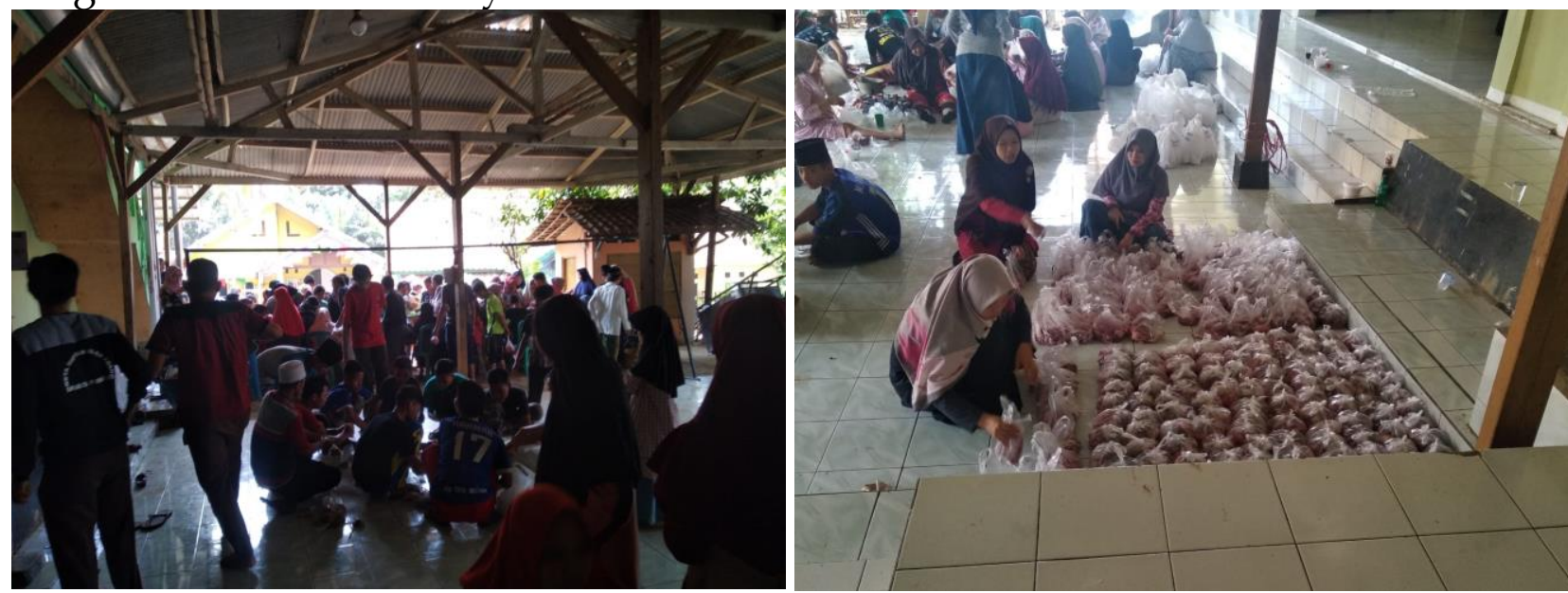

Gambar 3. Pengambilan Paket dagung Qurban

\section{KESIMPULAN}

Kesimpulan dari kegiatan pengabdian kepada masyarakat bagi jamaah dan Dewan Pengurus Pondok Pesantren Miftahurrohmah Sukarata Purwakarta untuk program Sosialisasi Sosial Ekonomi Dan Budaya Ibadah Qurban Di Pondok Pesantren Miftahurrohmah Sukarata Purwakarta adalah sebagai berikut. a) Peserta pelatihan sangat antusias ketika mengikuti pengabdian kepada masyarakat berupa ceramah dan diskusi. Para peserta dapat melihat manfaat pengabdian ini, yakni menambah pengetahuan pada hikmah ibadah qurban ditinjau dari asepk sosial budaya dan ekonomi; b) Berdasarkan sharing yang dilaksanakan pada saat diskusi, tidak ada kesan buruk dari peserta selama pelaksanaan pengabdian kepada masyarakat, baik dari segi sarana dan prasarana maupun penyampaian materi, hanya saja perlu dibuat dalam skala yang lebih luas. c) Pengabdian kepada masyarakat selanjutnya tetap diarahkan pada sharing masalah keilmuan dan praktik pengelolaan ibadah qurban yang dapat meningkatkan potensi ekonomi masyarakat. Oleh karena itu, pengembangan pengabdian selajutnya kemungkinan akan diarahkan pada pendampingan pengelolaan ibadah qurban yang dapat meningkatkan kesejahteraan masyarakat.

\section{UCAPAN TERIMAKASIH}

Penulis mengucapkan terima kasih dan apresiasi yang sebesar-besarnya kepada Jamaah dan Dewan Pengurus Pondok Pesantren Miftahurrohmah Sukarata Purwakarta yang telah membantu mensukseskan terlaksananya kegiatan pengabdian kepada masyarakat ini dengan lancar.

\section{DAFTAR PUSTAKA}

As-Suyuthi, Jalaluddin, and Jalaluddin Muhammad Ibnu Ahmad Al-Mahally. Tafsir

ADINDAMAS (Jurnal Pengabdian Kepada Masyarakat), Volume 1, Nomor 1, Juli 2021 http://journal.sties-purwakarta.ac.id/index.php/adindamas/

ISSN: xxxx-xxxx (Media Online) xxxx-xxxx (Media Cetak) 
Jalalain (Terjemahan). Imaratullah. Surabaya: Imaratullah, 2003.

Awaludin, Aan. "Program Pengabdian Kepada Masyarakat Teknik Handling Dan Penyembelihan Hewan Qurban." JPMP: Jurnal Pengabdian Masyarakat 2, no. 2 (2017): 84-97.

Cholili, Muhammad Sirojuddin. "Problematika Seputar Ibadah Qurban." Modeling: Jurnal Program Studi PGMI 2, no. 2 (2015).

Fadllan, Fadllan. "Rekonstruksi Pembangunan Ekonomi Berbasis Islam Telaah Pemikiran M. Umer Chapra." NUANSA: Jurnal Penelitian Ilmu Sosial dan Keagamaan Islam 15, no. 2 (December 18, 2018): 393. http://ejournal.stainpamekasan.ac.id/index.php/nuansa/article/view/ 2064.

Ka-nga, Muhammadrodee, Mawardi Djalaluddin, and Nur Taufiq Sanusi. "Hukum Distribusi Daging Qurban Kepada Non-Muslim Menurut Pandangan Majlis Agama Islam Provinsi Pattani Thailand Selatan." Jurnal Diskursus Islam 4, no. 2 (2016): 285-300.

Marlina, Evi, Isran Bidin, Zul Azmi, Adriyanti Agustina Putri, and Rama Gita Suci. "Wawancara Tentang Tinjauan Sosial Ekonomi Dan Budaya Ibadah Qurban." Jurnal Pengabdian UntukMu NegeRI 3, no. 2 (November 5, 2019): 243-247. http://ejurnal.umri.ac.id/index.php/PengabdianUMRI/article/view/1564.

Nur, Abdullah. "Ibadah Qurban Dalam Perspektif Hadis." Rausyan Fikr: Jurnal Studi Ilmu Ushuluddin dan Filsafat 12, no. 1 (2016): 144-160.

Saripudin, Iip. "Budaya Ibadah Qurban Di Lingkungan Pondok Pesantren Miftahurrohmah Sukarata Purwakarta," 2018.

Syahriar, Mohamad, and Mohamad Syahriar. "Representasi Makna Qurban Dalam Budaya Populer: Membaca Konsumerisme Melalui Analisis Semiotika Barthes Iklan Cetak PKPU Kurbanmu Kendaraanmu." LISKI: Lingkar Studi Komunikasi 2, no. 2 (2016): 147-179.

Team Al-Fatih Berkah Cipta. Al-Quranul Karim: Tafsir Perkata Tajwid Kode Arab. Jakarta Timur: PT. Insan Media Pustaka, 2012.

Wathan, Hubbul. "Pandangan Ulama Kota Medan Tentang Pelaksanaan Iddikhar Daging Qurban Di Rumah Zakat Medan-Sumatera Utara." Human Falah: Jurnal Ekonomi dan Bisnis Islam 4, no. 1 (2017). 